\title{
O RESUMO E A MOBILIZACÃO DOS RECURSOS METODOLOGICOS EM TESES DO DIREITO
}

\section{THE ABSTRACT AND THE MOBILIZATION OF THE METHODOLOGICAL RESOURCES IN LAW DISSERTATIONS}

\author{
Paula Carina de Araújo ${ }^{1}$ \\ Taysa Schiocchet ${ }^{2}$
}

\begin{abstract}
RESUMO
Discute a pesquisa em direito no Brasil e a mobilização dos recursos metodológicos de teses do Programa de Pós-graduação em Direito da Universidade Federal do Paraná. Objetiva analisar de que forma são mobilizados os recursos metodológicos de teses defendidas de 2017 a 2019 no Programa de Pós-graduação em Direito da Universidade Federal do Paraná, mediante a identificação da presença ou ausência dos itens obrigatórios (tema, objetivo, método, discussão e conclusão) nos seus resumos. Os objetivos específicos são: a) discutir aspectos epistemológicos caracterizadores da pesquisa em direito no Brasil; b) apresentar o resumo como item fundamental para a representação do conteúdo e dos recursos metodológicos das teses; c) contextualizar o PPGD da UFPR, no cenário da pós-graduação em direito brasileira; d) categorizar as teses defendidas entre 2017 e 2019 no PPGD/UFPR do ponto de vista da mobilização dos seus recursos metodológicos no resumo. Desenvolve uma pesquisa descritiva e faz uso da análise de conteúdo e da categorização para examinar e apresentar os dados da pesquisa. Utiliza os softwares Excel e Atlas.ti para a organização e visualização dos dados. 0 tema e os objetivos são os itens mais recorrentes e o método é o que menos vezes figura nos resumos que compõem o corpus da pesquisa. Apenas quatro teses apresentam resumos conforme a NBR 60282003 e contém todos os elementos descritos de forma explícita o que permite o reconhecimento inicial completo da pesquisa. 0 modelo de parecer é muito usado na forma de escrita dos textos, o que pode indicar uma confusão entre escrita científica e escrita profissional da área do direito. Palavras-chave: Comunicação científica. Resumo. Tese. Direito. Metodologia.
\end{abstract}

\section{ABSTRACT}

It discusses the law research in Brazil and the mobilization of the methodological elements of dissertations defended from 2017 to 2019 at the Law Graduate Program from Universidade Federal do Paraná. The purpose of this article is to analyze how the methodological elements of the dissertations defended from 2017 to 2019 at the Law Graduate Program of Universidade Federal do Paraná are mobilized by identifying the presence or absence of the abstract's mandatory items (topic, objective, method, discussion and conclusion). The specific objectives are: a) to discuss the aspects of law research in Brazil; b) to present the abstract as a fundamental item to represent the content and the methodological elements of the dissertations; $c$ ) to characterize the Law graduate programs in Brazil; d) to categorize the dissertations defended between 2017 and 2019, at the Law Graduate Program of Universidade Federal do Paraná, from the point of view of the mobilization of the methodological elements in the abstracts. It develops a descriptive research and it uses the content analysis and categorization to analyze and to present the research data. It uses the software Excel and Atlas.ti to organize and visualize the data. The theme and objectives are the most recurring items and the method is the one that appears less often in the abstracts from the corpus of this research. Only four dissertations present abstracts following the NBR 6028/2003 and they explicitly have all the descriptive elements which allow the initial complete research recognition. The legal opinion model is very used in the abstract writing, which may indicate a confusion between scholarly writing and professional writing in the law domain.

Keywords: Scholarly communication. Abstract. Dissertation. Law. Methodology.

1 Docente do Departamento de Ciência e Gestão da Informação e do Programa de Pós-graduação em Gestão da Informação da Universidade Federal do Paraná, Brasil. ORCID https://orcid.org/0000-0003-4608-752X. E-mail: paulacarina@ufpr.br.

2 Professora Adjunta da Faculdade de Direito e do Programa de Pós-Graduação em Direito da Universidade Federal do Paraná, Brasil. ORCID https://orcid.org/0000-0002-6703-9036. E-mail: taysa_sc@hotmail.com. 


\section{INTRODUÇÃO}

Ao revisar a literatura sobre a pesquisa jurídica no Brasil, percebe-se que é uma área carente de estudos mais recentes, especialmente, daqueles com foco nos aspectos metodológicos. Constata-se ainda a necessidade de atualização e confirmação do argumento sobre a prevalência do "modelo de parecer" como racionalidade operante na forma de produzir conhecimento na pós-graduação em direito. Dessa forma, esta pesquisa pretende contribuir para o aprofundamento desta discussão mediante a análise dos resumos de teses da área do Direito.

0 resumo é a "apresentação concisa dos pontos relevantes de um documento" segundo a norma técnica específica para a escrita dos resumos, a NBR 6028 de novembro de 2003, da Associação Brasileira de Normas Técnicas (ABNT). A mesma norma indica três tipos de resumo: o resumo crítico, 0 resumo indicativo e o resumo informativo (ABNT, 2003, p. 1). Da mesma forma, a ISO 214:2976 conceitua o resumo como uma representação abreviada e precisa do conteúdo do documento, sem interpretação ou crítica adicional (ISO, 1976).

Os documentos científicos como as dissertações, teses e artigos apresentam resumos informativos, que tem como objetivo "informar ao leitor finalidades, metodologia, resultados e conclusões do documento, de tal forma que este possa, inclusive, dispensar a consulta ao original" (ABNT, 2003, p. 1). Considerando a finalidade dos resumos informativos, a NBR 6028 estabelece que a primeira frase do resumo deve explicar o tema principal do documento de forma significativa. 0 objetivo, o método, os resultados e as conclusões da pesquisa devem ser ressaltados no resumo, que deve ser composto de uma sequência de frases concisas, afirmativas e não de enumeração de tópicos (ABNT, 2003).

Weinert (2010) argumenta que a função do resumo é muitas vezes esquecida e subestimada. Acrescenta também que a preparação de um resumo convincente é uma habilidade necessária e reconhecida do pesquisador. Por outro lado, Leitão e Simões (2017, p. 825) constataram, que "o resumo, através das duas propriedades intrínsecas, permite o acesso equitativo à informação e ao conhecimento, na medida em que apresenta a informação condensada e organizada numa macroestrutura".

Como parte de um documento científico, o resumo é um meio privilegiado de divulgação e seleção do conhecimento produzido no que se refere à literatura científica. Também é um instrumento de pesquisa, por exemplo, em bases de dados científicas (GUIMARÃES, 2005; SIMÕES, 2015).

0 título, o resumo e as palavras-chave de um documento científico tem por finalidade representar a informação nele contida, de forma sucinta e sistematizada. Essa representação visa a dar subsídios 
para que o leitor reconheça 0 assunto tratado no trabalho e decida, a partir desses elementos, se 0 documento é ou não do seu interesse. Além disso, eles são os principais elementos de descrição dos documentos científicos em catálogos de bibliotecas e bases de dados nacionais e internacionais, ou seja, funcionam como porta de entrada ou filtro inicial para acesso aos trabalhos integrais.

A redação do resumo, além de representar o domínio dos recursos metodológicos na escrita científica, é um dos fatores determinantes para a que a pesquisa seja encontrada por meio dessas fontes de informação. Diante disso, questiona-se como são mobilizados os recursos metodológicos de teses do Programa de Pós-graduação em Direito da Universidade Federal do Paraná (UFPR), defendidas entre 2017 e 2019 ?

Portanto, o objetivo geral desta pesquisa é analisar de que forma são mobilizados os recursos metodológicos de teses defendidas de 2017 a 2019 no Programa de Pós-graduação em Direito da Universidade Federal do Paraná (UFPR), mediante a identificação da presença ou ausência dos itens obrigatórios (tema, objetivo, método, discussão e conclusão) nos seus resumos.

Para alcançar o objetivo geral, foram definidos os seguintes objetivos específicos: a) discutir aspectos epistemológicos caracterizadores da pesquisa em direito no Brasil; b) apresentar o resumo como item fundamental para a representação do conteúdo e dos recursos metodológicos das teses; c) contextualizar o PPGD da UFPR, no cenário da pós-graduação em direito brasileira; d) categorizar as teses defendidas entre 2017 e 2019 no PPGD/UFPR do ponto de vista da mobilização dos seus recursos metodológicos no resumo.

Considerando o exposto, desenvolveu-se uma pesquisa descritiva e aplicou-se a análise de conteúdo (BARDIN, 2011) e a categorização para alcançar os objetivos da pesquisa. Foram examinados os resumos das teses defendidas de 2017 a 2019 no PPGD/UPR. Os softwares Excel e Atlas.tiapoiaram a organização, análise e apresentação dos dados da pesquisa. A pesquisa foi desenvolvida em três etapas.

A primeira consistiu na pré-análise. Nessa etapa foram escolhidos os documentos a serem examinados, formuladas as hipóteses, os objetivos e as categorias que apoiaram a interpretação final. A seleção das teses foi feita a partir de uma lista fornecida pela coordenação do PPGD/UFPR. Os textos completos das teses foram obtidos por meio de busca no Repositório Digital Institucional da UFPR e, aqueles que não estavam disponíveis foram solicitados à Biblioteca de Ciências Jurídicas do Sistema de Bibliotecas da UFPR.

Na fase de exploração do material os dados das teses (autor, título, orientador, ano de defesa, área de concentração, palavras-chave e resumos) foram organizados em uma planilha Excel juntamente 
com as categorias pré-definidas, a saber: tema explícito, tema implícito, objetivos explícitos, objetivos implícitos, método explícito, método implícito, resultados/conclusões explícitos, resultados/conclusões implícitos. Fez-se a análise qualitativa dos dados por meio da leitura e categorização dos resumos.

Ainda na fase de exploração, os resumos das teses foram carregados no software Atlas.ti e foi gerada uma lista de palavras 3 a serem buscadas nos resumos. Fez-se a contagem das palavras relacionadas aos elementos metodológicos presentes nos resumos e foi criada uma planilha e gráficos com essas informações, apresentados na próxima seção. Por fim, na última fase, o conjunto dos dados foi interpretado e resultou em inferências e constatações no contexto da pesquisa.

Após a introdução da pesquisa, a próxima seção traz um panorama da pesquisa em direito no Brasil com uma descrição da pós-graduação em direito brasileira e a apresentação do Programa de Pós-Graduação em Direito da UFPR. A análise dos resumos das teses defendidas de 2017 a 2019 no PPGD/UFPR é apresentada na seção três. Por fim, tem-se as considerações finais da pesquisa.

\section{PESQUISA EM DIREITO NO BRASIL}

0 que temos a falar sobre a pesquisa em direito no Brasil? Alguns intelectuais, juristas e nãojuristas, estudaram essa questão nas duas últimas décadas e os principais aspectos dessas análises são apresentados a partir de três textos considerados fundamentais para compreender o cenário da produção científica no campo do Direito.

Um dos primeiros textos ${ }^{4}$ é de autoria do cientista político Marcos Nobre (UNICAMP). Em 2002 ele sistematizou uma discussão coletiva que ocorria no CEBRAP "sobre o significado da pesquisa em Direito no Brasil e sua relação com a prática profissional” (RODRIGUEZ, 2004, p.1). Neste texto, publicado em 2004, Nobre faz um diagnóstico da pesquisa em Direito no Brasil e qualifica o campo como de "relativo atraso" se comparado com as demais áreas das ciências humanas. Isso teria ocorrido em função de dois fatores. Primeiro, a indistinção entre prática profissional, teoria/pesquisa acadêmica e ensino. Segundo, o isolamento do Direito.

Nobre argumenta que, situado historicamente no bojo do projeto nacional-desenvolvimentista de implantação das universidades no Brasil, esse isolamento epistemológico do Direito decorreu de uma espécie de nobreza quase que exclusiva da área. Alicerçada na sua tradição e na suposta posição

3 Lista de palavras: Conclui; conclui-se; concluiu; conclusao; conclusão; conclusoes; conclusões; defende; método; método; metodología; objetivo; objetivos; rejeitada; rejeitar; resultado; resultados; sustenta; sustentar; tema; temática

4 Na década de 80 o CNPq fez um diagnóstico sobre a área do Direito. Afirmou que a pesquisa jurídica estaria comprometida. 
de "ciência rainha", o Direito parecia afastar as demais disciplinas das ciências humanas, as quais eram marcadas pela excelência da ciência moderna. Em função disso, o Direito não teria acompanhado os avanços da pesquisa acadêmica dos últimos 50 anos (NOBRE, 2004, p. 5-6).

E ainda que essa relação tenha sofrido alterações em função do que Nobre (2004, p. 6) chama de “juridificação das relações sociais” promovida pela Constituição de 1988, esse afastamento permanece:

Os cientistas sociais ainda costumam olhar com desconfiança a produção teórica em direito, já que aí não encontram os padrões científicos requeridos, e os teóricos do direito parecem continuar a ver a produção em ciências humanas como externa ao seu trabalho, dizendo-lhe respeito apenas indiretamente.

Como consequência desse cenário, Nobre (2004, p. 7-15) vai enfatizar justamente que 0 ensino jurídico não se fundamenta em pesquisas, mas em resultados da prática jurídica profissional (do advogado, juiz, promotor), estreitando sobremaneira a concepção de teoria jurídica presente na produção nacional. E isso estaria diretamente vinculado com o modelo de parecer (e da atividade advocatícia ${ }^{5}$ ) como forma-padrão predominante de argumentação na produção acadêmica em direito. Essa questão poderia ser explicada, ao menos em parte, pela confusão corrente que se faz entre solucionar algo (técnica jurídica, prática) e compreender/explicar algo (teoria, pesquisa).

Dois anos mais tarde, impulsionados por esse diagnóstico de Nobre, Fragale Filho e Veronese (2004), publicam uma pesquisa apresentando alguns contrapontos e atualizações. Segundo os autores, o Direito apresenta peculiaridades e por isso seu desenvolvimento e práticas seriam distintos das demais áreas das ciências humanas. Além disso, apontam a fragilidade do pressuposto de que o Direito não atingiu níveis qualitativos de excelência na pesquisa, por se fundar num relatório do CNPq da década de 80 e em especulações. Por isso, os autores propõem uma análise quanti-quali, mais ampla e completa, a ser feita a partir das produções acadêmicas realizadas nos PPGDs.

Os autores apresentam, então, alguns dados da época. Destacam que a pós-graduação em direito triplicou sua oferta entre 1981-2001, sendo que entre 1997-2004 ela dobrou de tamanho, de 25 para 52 PPGs. Mencionam que a participação de universidades privadas era expressiva, sobretudo nos cursos de mestrado e que oito PPGDs, da região sul e sudeste na sua maioria, concentravam o contingente discente. Essa expansão, então, proporcionou o aumento da produção de pesquisa e publicações na área, mas não necessariamente um salto qualitativo. Um indício disso: a área não

50 autor faz uma distinção entre ambos e afirma que o modelo de parecer não se afasta mas reforça a lógica da atividade advocatícia, no sentido de ser parcial e não embasar-se no conjunto de material disponível e em um padrão de racionalidade, mas apenas naquilo que interessa à tese. 
possui programa com nota máxima e, portanto, não atinge os melhores padrões internacionais de pesquisa. 0 que, na análise dos autores, não permite concluir o atraso do Direito em comparação com áreas vizinhas. Até porque constatou-se que essas áreas eram muito mais beneficiadas com fomento à pesquisa em comparação com o Direito (FRAGALE FILHO; VERONESE, 2004, p. 55-59).

Fragale Filho e Veronese (2004, p. 67) rechaçam, portanto, a hipótese do atraso em relação as outras áreas (NOBRE, 2004) e sustentam que na verdade esse "'atraso', não percebido por Nobre em sua reflexão, consiste na ausência de uma reflexão epistemológica e metodológica mais consistente na área jurídica”.

Entendemos, contudo, que esses dois artigos não trazem análises e conclusões necessariamente opostas, mas complementares. Ambos os textos reconhecem fragilidades qualitativas no modo de fazer pesquisa científica no Direito, as quais dizem respeito a aspectos epistemológicos, metodológicos e de fomento, mas também mercadológicos. É o que acontece quando a demanda da área do Direito para a formação de docente, especialmente na rede privada de ensino superior, faz privilegiar o ensino em detrimento da pesquisa. Ou ainda, quando as avaliações científicas, dominadas por grandes corporações do mercado editorial, geram modelos dominantes e vieses, por vezes, excludentes de áreas do conhecimento e regiões geográficas.

Seguindo essa linha de raciocínio, uma análise mais atualizada, feita por Spera e Mugnaini (2019, p. 1) na área da Ciência da Informação, corrobora, ao menos em parte, esse diagnóstico. Ao reconhecer especificidades e hábitos de publicação na área do Direito, os autores identificaram que grande parte da produção jurídica ainda é em formato de parecer, o que gera, dentre outras razões, um distanciando-se do atual modelo de avaliação. Não isento de críticas, esse modelo é fundado no tripé "base de dados - cobertura internacional relevante - indicadores de citação". Esses critérios acabam por desfavorecer a área. Contudo, importa frisar que o distanciamento desse modelo, não é uma característica exclusiva da área do Direito, mas das Ciências Sociais e Humanas (soft science) como um todo e no mundo todo.

\subsection{Programas de Pós-Graduação em Direito no Brasil}

Ao discutir a pesquisa em Direito no Brasil é fundamental apresentar o contexto atual dos Programas de Pós-graduação dessa área. 0 Gráfico 1 apresenta a evolução do número de cursos e programas de pós-graduação stricto sensu da Área de Direito de 2013 a 2019. Houve um aumento significativo no número de programas, 28 programas foram criados de 2013 a 2019. 
Gráfico 1: Cursos de Pós-graduação em Direito stricto sensu da Área de Direito (2013 a 2019)

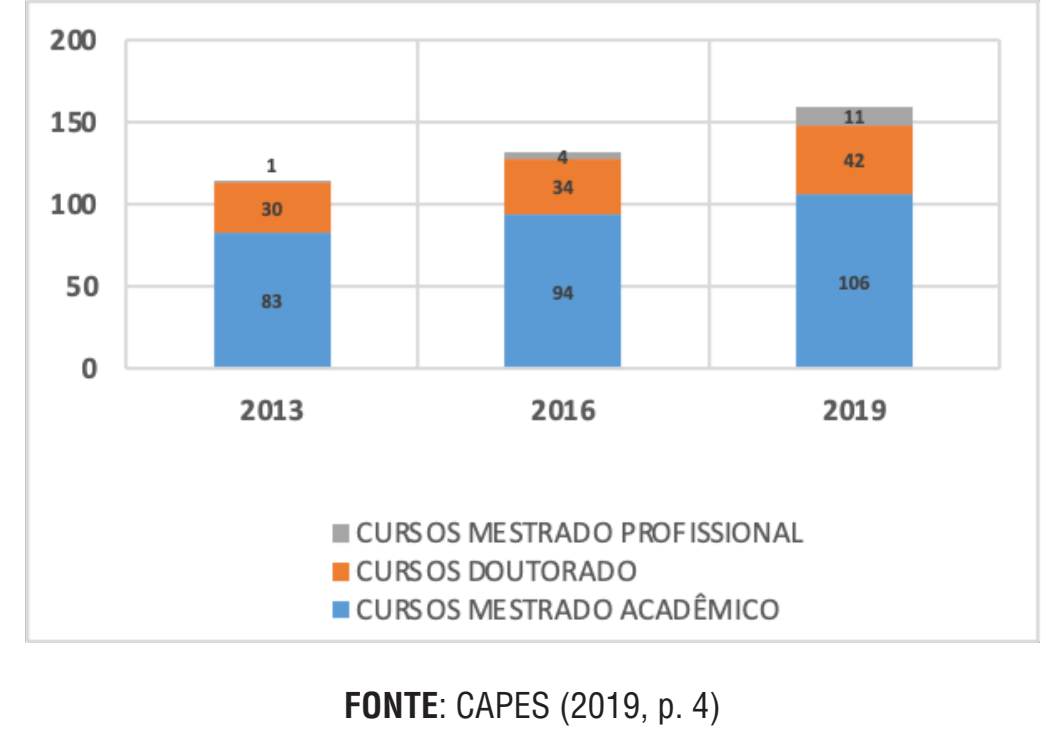

Os dados relativos à distribuição dos programas por vinculação administrativa no ano de 2019 são apresentados no Gráfico 2. A área do direito conta com a maioria de cursos oferecidos por instituições particulares, um total de 72 programas, contra 37 oferecidos por universidade públicas federais e estaduais. E, considerando os dados apresentados por Fragale Filho e Veronese (2004), a quantidade de programas dobrou desde 2004.

Gráfico 2: Distribuição dos programas por vinculação administrativa

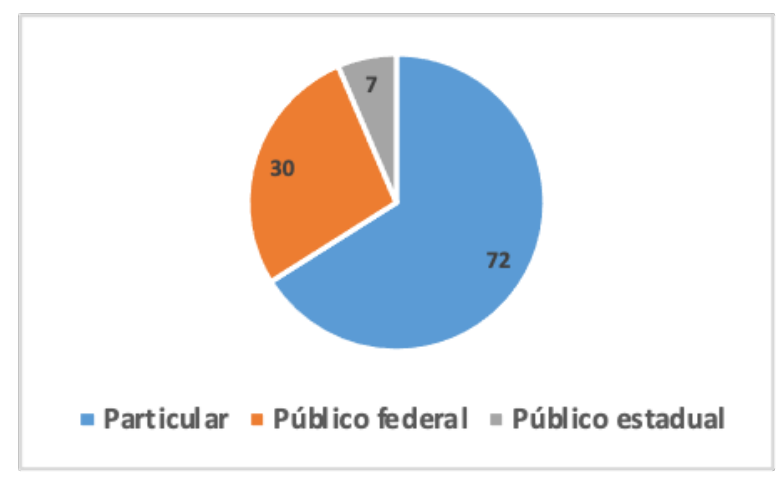

FONTE: CAPES (2019, p. 5)

A região Sudeste do Brasil tem a maior concentração de programas de pós-graduação em Direito, totalizando 63 programas. E, a região Norte do Brasil tem a menor concentração totalizando 5 programas, sendo que apenas um deles oferece curso de Doutorado (TABELA 1). Esses dados evidenciam o desequilíbrio na distribuição de programas no Brasil. Também reproduzem a iniquidade e a desigualdade entre as regiões, presente em setores como o econômico, financeiro e social. 
Quadro 1: Distribuição dos cursos de pós-graduação stricto sensu da Área de Direito (2019).

\begin{tabular}{|c|c|c|c|c|}
\hline REGIÃO & $\begin{array}{c}\text { MESTRADOS } \\
\text { ACADÊMICOS }\end{array}$ & $\begin{array}{c}\text { MESTRADOS } \\
\text { PROFISSIONAIS }\end{array}$ & DOUTORADOS & TOTAL \\
\hline Norte & 5 & 0 & 1 & 5 \\
\hline Nordeste & 19 & 1 & 6 & 26 \\
\hline Centro-oeste & 9 & 4 & 3 & 16 \\
\hline Sul & 30 & 4 & 14 & 48 \\
\hline Sudeste & 43 & 2 & 18 & 63 \\
\hline Total & 106 & 11 & 42 & 159 \\
\hline
\end{tabular}

FONTE: CAPES (2019, p. 6)

0 gráfico 3 demonstra que a cada ano, de 2016 a 2018, houve um aumento no número de docentes dos PPGDs brasileiros para: permanente, colaborador e visitante. São 210 novos docentes no total. Até o momento de realização desta pesquisa não estavam disponíveis no GEOCAPES os dados referentes a 2019.

Gráfico 3: Docentes dos programas de pós-graduação em Direito de 2016 a 2018.

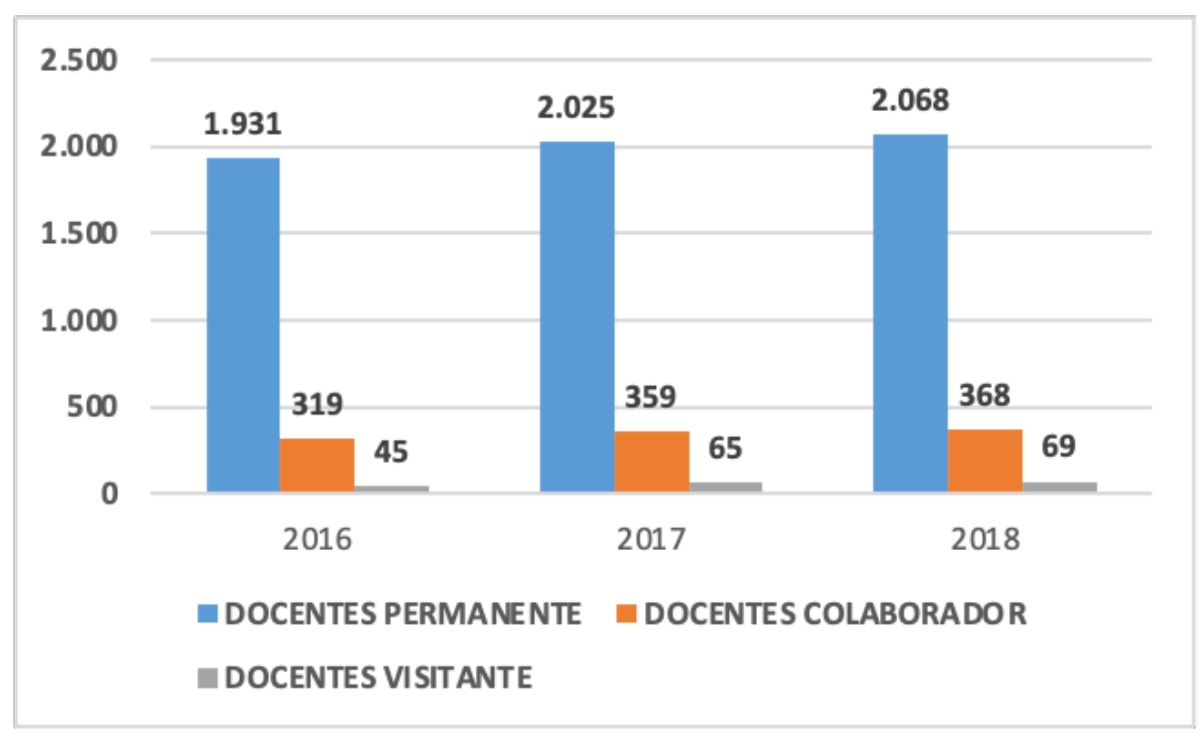

FONTE: GEOCAPES (2019)

0 número de discentes em PPGDs brasileiros teve um aumento significativo no período de 2016 a 2018, conforme Tabela 5. Nesse período, 1.460 novas vagas foram abertas nos programas. Os dados obtidos por meio do GeoCAPES (2019) ainda evidenciam que no mesmo período os programas de instituições particulares aumentaram em 905 o número de vagas e nos programas de instituições privadas 0 aumento foi de 555 vagas. 
Gráfico 4: Discentes dos programas de pós-graduação em Direito de 2016 a 2018.

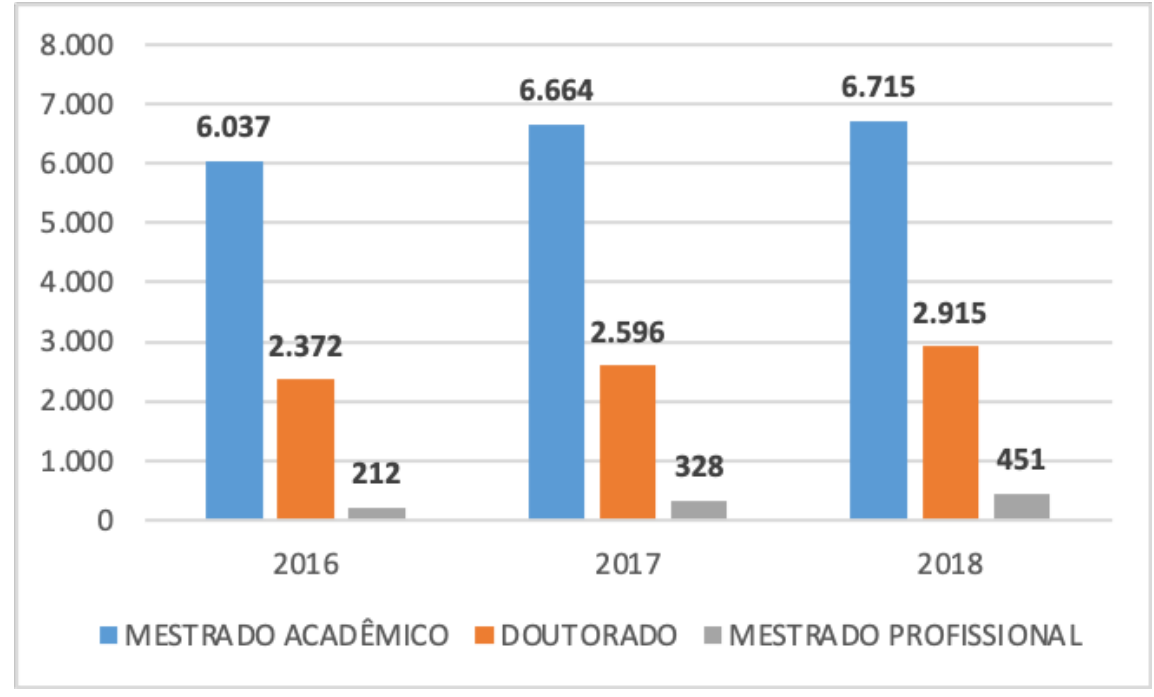

FONTE: GEOCAPES (2019)

Para fins da avaliação do Sistema Nacional de Pós-graduação, o Direito faz parte da grande área de Ciências Sociais Aplicadas, dentro do colégio de Humanidades. No total, 49 áreas são avaliadas com 0 objetivo de garantir a qualidade da pós-graduação brasileira e identificar assimetrias regionais e de áreas estratégicas do conhecimento para orientar ações de indução na criação e expansão de programas no território nacional (CAPES, 2014).

0 Quadro 2 apresenta a distribuição do número de programas por conceito da avaliação quadrienal da Coordenação de Aperfeiçoamento de Pessoal de Nível Superior (CAPES).

Quadro 2: Distribuição do Programas por Conceito.

\begin{tabular}{|c|c|}
\hline CONCEITO & $\begin{array}{c}\mathbf{N}^{\mathbf{0}} \text { DE } \\
\text { PROGRAMAS }\end{array}$ \\
\hline $\mathbf{3}$ & 47 \\
\hline $\mathbf{4}$ & 36 \\
\hline $\mathbf{5}$ & 12 \\
\hline $\mathbf{6}$ & 11 \\
\hline TOTAL & 106 \\
\hline
\end{tabular}

FONTE: CAPES (2019)

Os programas são avaliados pela CAPES e pela comunidade científica por meio de consultoria ad hoc. A avaliação acontece baseada em uma ficha de avaliação com critérios pré-definidos e os conceitos variam de 1 a 7 , sendo que os programas que recebem nota 6 ou 7 são considerados programas de 
excelência. 0 PPGD da UFPR recebeu 0 conceito nota 6 na última avaliação quadrienal (2013-2016) e será apresentado na próxima seção.

\subsection{Programa de Pós-Graduação em Direito da UFPR}

0 Programa de Pós-graduação (PPGD) da Universidade Federal do Paraná (UFPR) tem como objetivos preparar pessoal qualificado para o magistério superior na área jurídica e qualificar docentes para as atividades de pesquisa, no campo da ciência jurídica (OBJETIVOS..., 2020). 0 curso de Mestrado teve início em 1982 e o curso de Doutorado em 1994, o PPGD foi avaliado pela CAPES com nota 6 nas duas últimas avaliações quadrienais (DAD0S..., 2020).

Três áreas de concentração, criadas em 2001, estabelecem a organização do programa conforme o Quadro 3:

Quadro 3: Áreas de Concentração e Linhas de Pesquisa.

\begin{tabular}{|l|l|}
\hline \multicolumn{1}{|c|}{ Área de Concentração } & \multicolumn{1}{c|}{ Linha de Pesquisa } \\
\hline \multirow{2}{*}{ Direitos Humanos e Democracia } & Cooperativismo e Economia Solidária \\
\cline { 2 - 2 } & Cidadania e Inclusão Social \\
\hline \multirow{2}{*}{ Direito do Estado } & Perspectivas da Dogmática Crítica \\
\cline { 2 - 2 } & Direito, Poder e Controle \\
\hline \multirow{2}{*}{ Direito das Relações Sociais } & Direito, Tutela e Efetividade \\
\cline { 2 - 2 } & Novos Paradigmas do Direito \\
\hline
\end{tabular}

FONTE: LINHAS... (2020)

A distribuição dos docentes por área de concentração no PPGD/UFPR é apresentada na Figura 1 por meio de uma rede de relações. 
Figura 1: Relação entre os docentes e as áreas de concentração do PPGD/UFPR.

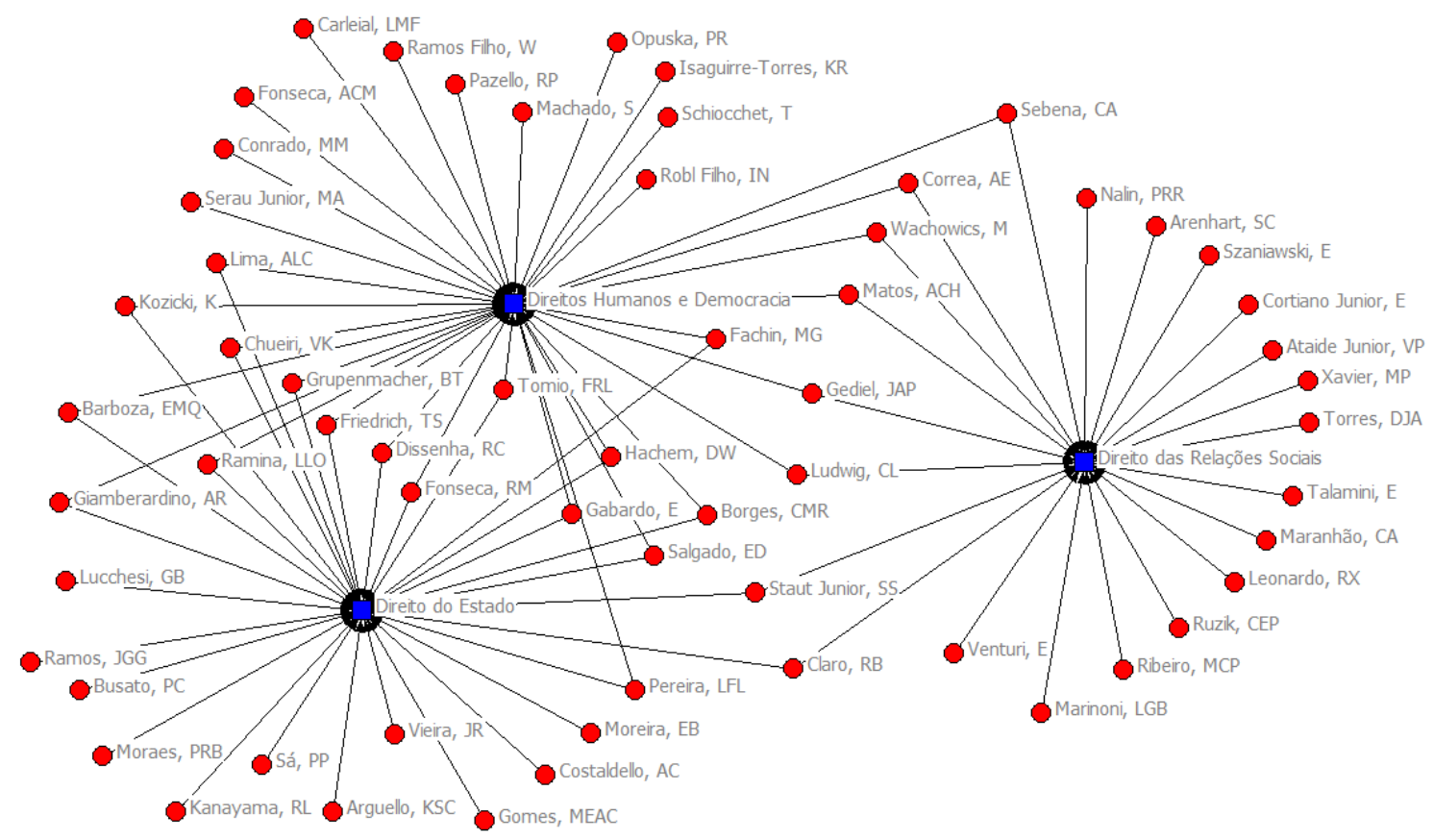

FONTE: Dados fornecidos pelo PPGD/UFPR (2020)

Os nós em vermelho representam os docentes e os azuis são as três áreas de concentração. A área de concentração Direitos Humanos e Democracia é a que tem mais docentes vinculados, totalizando 34. A área de concentração Direito do Estado tem 30 docentes vinculados e Direito das Relações Sociais tem 23 docentes. Dos 62 docentes do PPGD/UFPR, 25 estão vinculados a duas áreas de concentração simultaneamente.

0 PPGD/UFPR conta com um total de 62 docentes, sendo que 47 são permanentes e 15 são colaboradores. 0 gráfico 5 demonstra a evolução desse número de 2016 a 2020.

Gráfico 5: Docentes do PPGD/UFPR de 2016 a 2020.

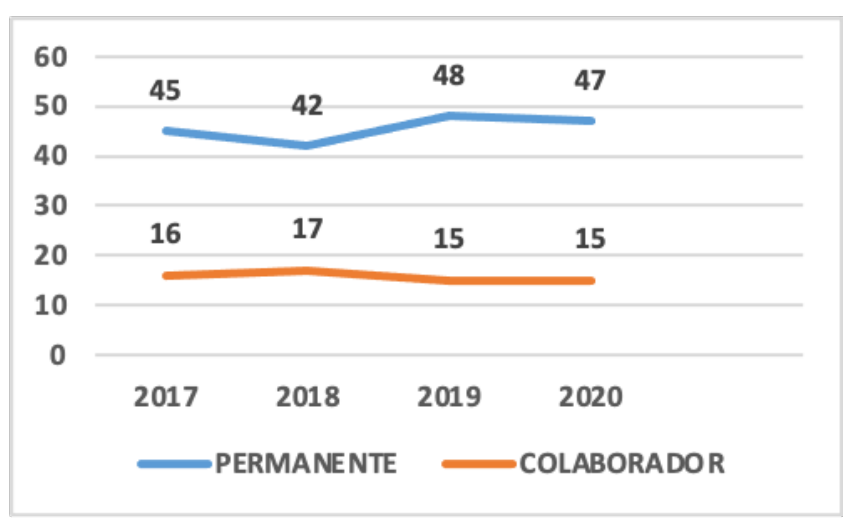

FONTE: Coleta CAPES (2020) 
No ano de 2020 o PPGD/UFPR tinha 184 alunos matriculados, sendo que 86 são alunos de mestrado e 98 de doutorado. 0 gráfico 6 demonstra a evolução do número de discentes de 2016 a 2020.

Gráfico 6: Discentes Matriculados no PPGD/UFPR de 2016 a 2019.

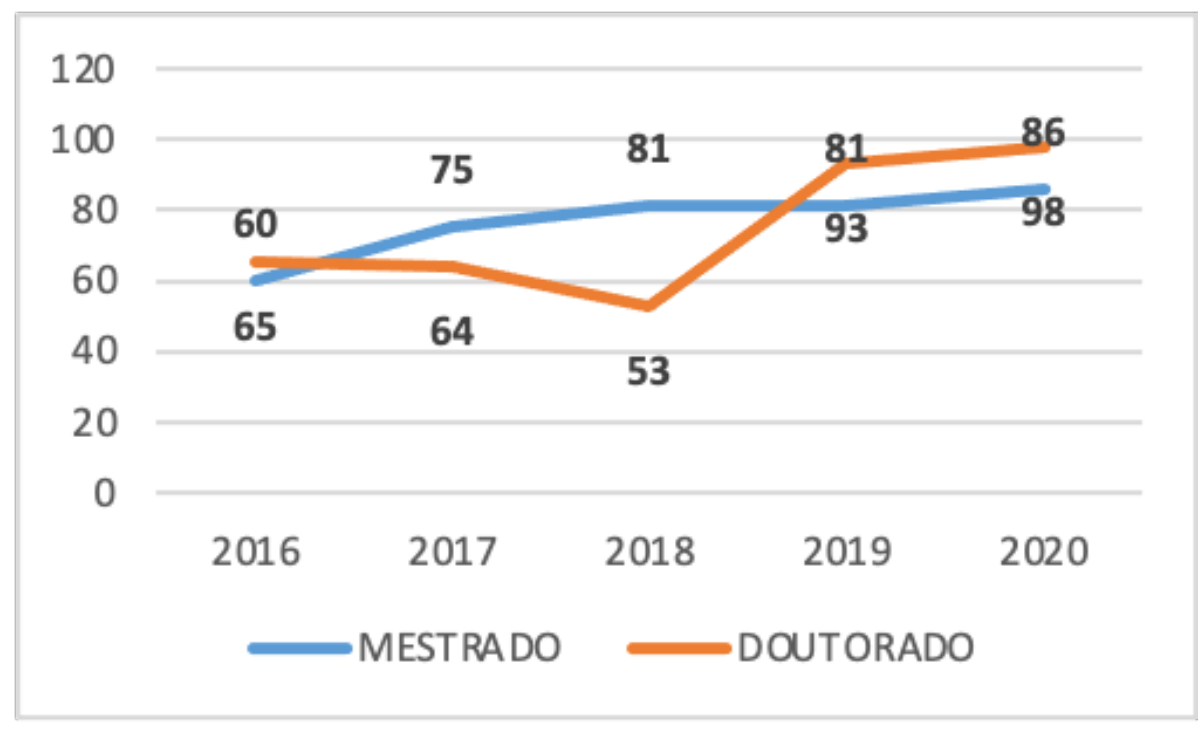

FONTE: CAPES (2020)

A Resolução nº. 69/05-CEPE fixa o currículo do PPGD/UFPR para os curso de Mestrado e Doutorado. 0 curso de Mestrado está estruturado em 36 disciplinas e 0 curso de Doutorado em 30 disciplinas, distribuídas entre disciplinas fundamentais (obrigatórias), básicas e eletivas (optativas). Destaca-se que há disciplinas comuns para 0 mestrado e 0 doutorado e mesmo que 0 aluno já tenha cursado a disciplina no mestrado, é obrigatório cursá-la no doutorado. A disciplina Metodologia da Pesquisa Jurídica faz parte do conjunto de disciplinas fundamentais do currículo e equivale a dois créditos (UFPR, 2005). Apesar de ser uma disciplina fundamental para a escrita da tese, a disciplina de metodologia tem a menor carga horária entre todas as disciplinas.

Por ser um programa de excelência, figurando dentre os 11 programas avaliados com nota 6 pelas CAPES na última avaliação quadrienal (2013-2016), o PPGD/UFPR foi estudado nesta pesquisa. Mais precisamente, os objetos de estudo foram os resumos das teses defendidas entre 2017 e 2019. Considerando que o resumo explicita de forma concisa os itens metodológicos de validação e inerentes à produção científica, esse elemento das teses foi analisado tendo em vista sua finalidade de representar a informação contida nesses documentos; segundo, por contribuírem para a visibilidade das pesquisas desenvolvidas pelos programas de pós-graduação. Na próxima seção são apresentados os resultados das análises. 


\section{ANÁLISE DOS RESUMOS DAS TESES DEFENDIDAS ENTRE 2017 E 2019 NO PPGD/UFPR}

Os resumos das teses defendidas nos anos de 2017, 2018 e 2019 no PPGD/UFPR foram objeto desta pesquisa. Foram analisados 45 resumos no total. A distribuição por ano de defesa é apresentada no Gráfico 7. Destaca-se o ano de 2017 com o maior número de defesas, totalizando 18.

Gráfico 7: Distribuição das teses por ano de defesa.

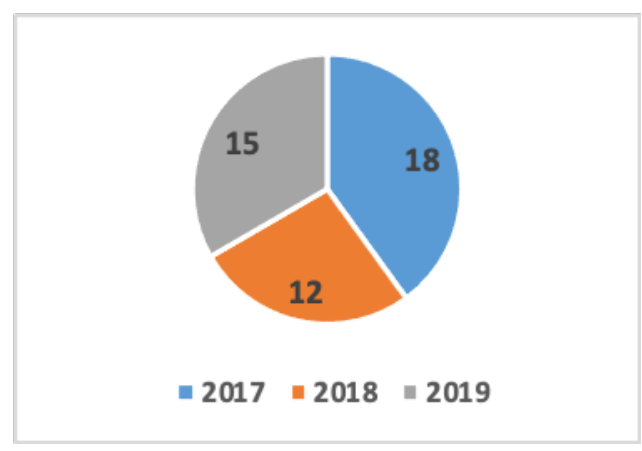

FONTE: As autoras (2020)

0 Gráfico 8 apresenta a distribuição das teses analisadas por área de concentração. Chama a atenção o desequilíbrio na quantidade de teses defendidas em relação ao número de docentes, especialmente na área de concentração Direitos Humanos e Democracia, que totalizou apenas quatro defesas nos três anos. Como demonstrado na Figura 1, a área de concentração com menor número de teses defendidas no período analisado, é também aquela com maior número de professores vinculados. Por outro lado, as áreas de concentração Direito do Estado e Direito das Relações Sociais tiveram 21 e 20 teses defendidas respetivamente.

Gráfico 8: Teses defendidas no PPGD/UFPR de 2017 a 2019 por Área de Concentração.

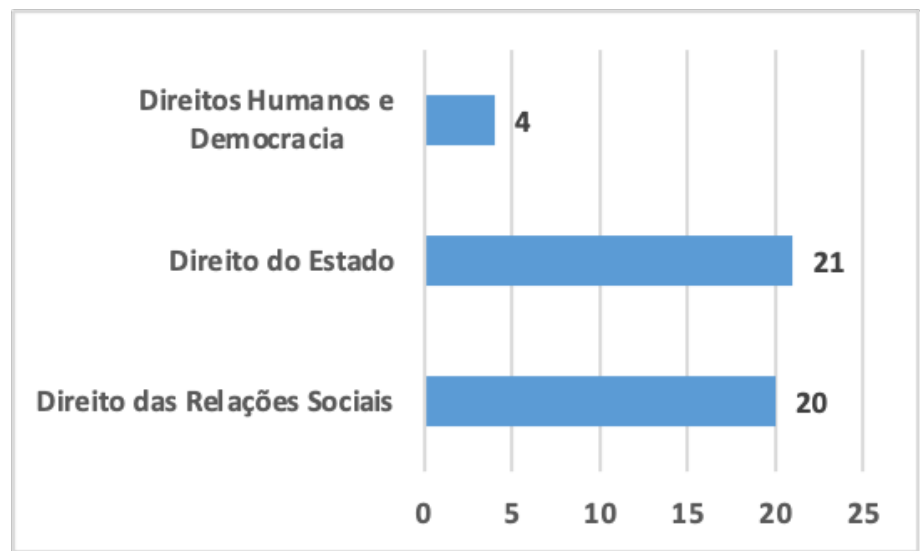

FONTE: CAPES (2020) 
A partir desses dados cabe um olhar atento para a área de concentração Direitos Humanos e Democracia. Do total de 34 docentes da área, apenas oito não têm vinculação com outra área de concentração do programa. 0 desequilíbrio revelado tem causa incerta, mas pode estar relacionado ao modelo de processo seletivo do programa até 2017. Pois, os editais não descreviam as áreas de concentração e não indicavam as linhas de pesquisa, sem muito controle de vagas por professor, área e linha de pesquisa. Em 2018 o edital do processo seletivo do PPGD/UFPR passou a prever a seleção por área de concentração, o que possivelmente impactará na distribuição das vagas entre as áreas e respectivos docentes.

Seguindo na análise do corpus coletado, foi elaborada uma lista de critérios relacionadas aos elementos metodológicos das teses que devem figurar no resumo. Para isso, as palavras indicadas na nota 1 foram buscadas em cada um dos resumos por meio do software Atlas.ti. Esse levantamento gerou 0 Gráfico 9 e 0 Gráfico 11. 0 Gráfico 9 demonstra a quantidade de resumos que contém as palavras que podem evidenciar a presença dos itens tema, objetivo, metodologia, resultados e conclusão. Palavras relacionadas aos objetivos da tese são as mais recorrentes, aparecem em 15 resumos. 0 segundo grupo de palavras mais recorrente relaciona-se com a metodologia da pesquisa, totalizando 13 resumos.

Gráfico 9: Teses que contém palavras relacionadas aos itens obrigatórios dos resumos.

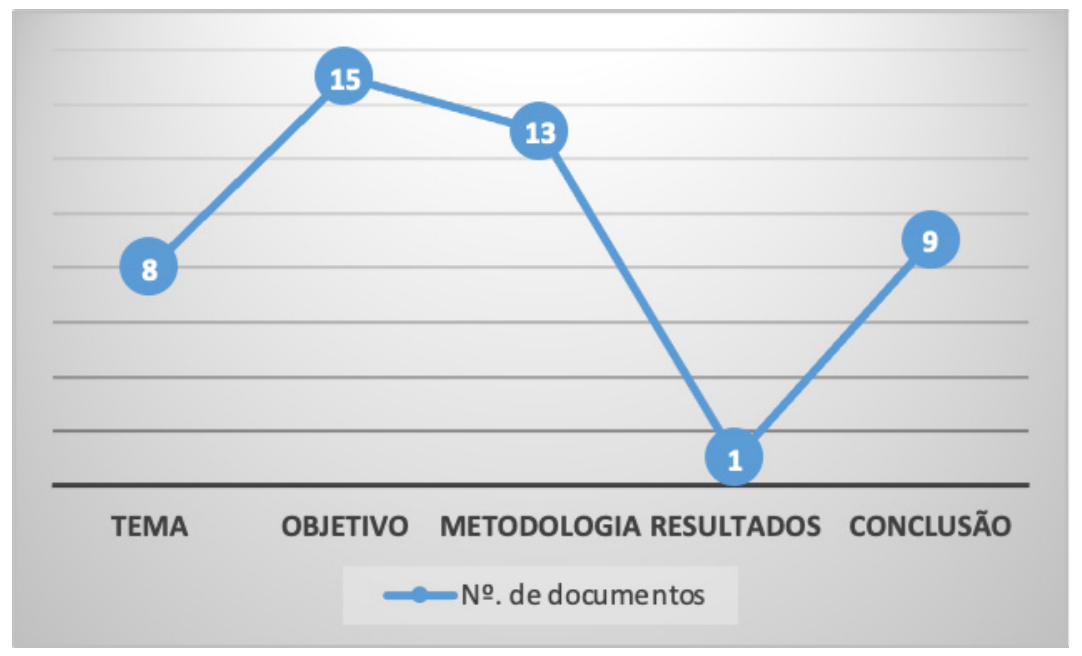

FONTE: Dados da pesquisa (2020)

Uma análise quantitativa da contagem de palavras dos resumos das teses analisadas levaria as autoras a inferirem que 0 objetivo e a metodologia são os recursos metodológicos mais recorrentes nos documentos analisados (GRÁFICO 9). Entretanto, para complementar esta análise e enriquecer os 
resultados, a segunda etapa da pesquisa consistiu em desenvolver uma análise qualitativa dos resumos por categorização temática (GRÁFICO 10).

Gráfico 10: Presença ou ausência dos itens obrigatórios nos resumos

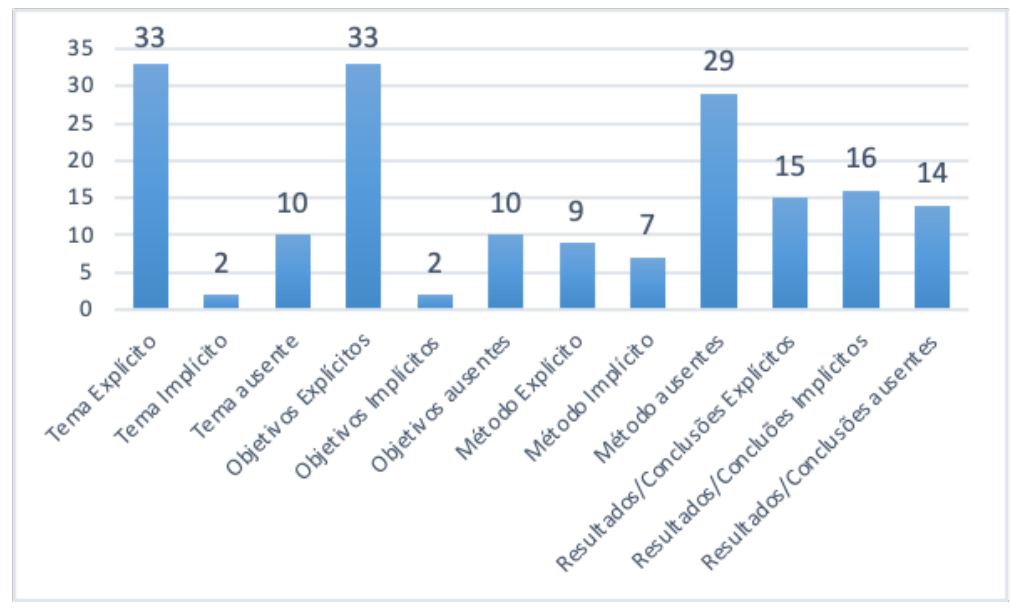

FONTE: Dados da pesquisa (2020)

Considerando o que estabelece a NBR 6028/2003 e as finalidades do resumo, quatro categorias foram definidas para a análise, a saber: tema, objetivo, metodologia, resultados/conclusões. Ressalta-se que não é comum o uso da palavra resultados na pesquisa em direito, por isso, resultados e conclusões foram considerados como uma única categoria. A análise se deu por meio da leitura em profundidade dos resumos e verificação da presença ou ausência dessas categorias de forma explícita ou implícita, conforme 0 gráfico 10.

A contagem de palavras relacionadas aos itens obrigatórios do resumo, apresentada no Gráfico 9, indica oito ocorrências para a palavra tema. Entretanto, a análise de conteúdo dos resumos (GRÁFICO 10), evidenciou que o tema está explícito na maioria dos resumos de forma explícita (33), mas nem sempre aparece nas primeiras frases, contextualizando a pesquisa. Dois resumos apresentam 0 tema de forma implícita e os 10 restantes não apresentam o tema da pesquisa no resumo. Essa é uma diferença, em parte, esperada e explicada pela própria diferença qualitativa da análise de conteúdo manual e da analise de conteúdo via software.

A tese de Cirino (2017, p. 11) exemplifica a apresentação do tema explicitamente no resumo da tese, da seguinte forma: "o presente trabalho questiona a possibilidade de reconhecimento do trabalho da mulher, que permita a autorrealização pela contribuição da atividade laboral, diante da precarização do trabalho humano no capitalismo pautado pelo programa neoliberal”. 
Em geral a categoria objetivo está explícita no texto, totalizando 33 resumos (GRÁFICO 10). 0 resumo da tese de Brighente (2019, p. 9) é um exemplo da apresentação do objetivo geral da tese de forma explícita. A autora afirma "o objetivo da pesquisa é estudar o problema da condição jurídica criminal do escravo no Império do Brasil, investigação que toma concretamente como ponto de partida a Comarca de Castro".

Hansen (2019, p. 9) também apresenta o objetivo geral de forma explícita: "0 presente estudo objetiva compreender a história da formação do primeiro Código Florestal Brasileiro, produzido entre 1931 e 1934". Além disso, o resumo apresenta os pontos tratados nos capítulos da tese.

Nem sempre se pode precisar, contudo, se os textos fazem referência ao objetivo geral do trabalho propriamente ou aos objetivos específicos. É importante lembrar que o objetivo geral da pesquisa expressa a preocupação global que se pretende estudar. Já os objetivos específicos são um detalhamento do objetivo geral e definem etapas que devem ser realizadas para o seu alcance.

Alguns resumos evidenciam essa dificuldade de diferenciação entre objetivo geral e específicos. 0 resumo da tese de Câmara (2017a, p. 6), por exemplo, apresenta um objetivo que parece estar relacionado a uma etapa específica da pesquisa e não ao trabalho como um todo, ao mencionar que: "[...] examinam-se, neste trabalho, a compatibilidade e a viabilidade da leitura integrada do direito ao desenvolvimento e da liberdade informática na sociedade em rede".

Por outro lado, o resumo da tese de Hasson (2018, p. 7) evidencia a presença do objetivo geral da pesquisa de forma explícita:

A presente tese tem como objetivo geral o estudo crítico dos fundamentos do Direito Internacional Privado (DIPr), tomando-se como fio condutor a noção de função manifesta defendida por Robert Merton com vistas a identificar a maneira com que esta função manifesta afeta a criação, interpretação e aplicação das regras de conflito.

Ainda quanto à explicitação do objetivo da pesquisa, outro exemplo pode ser apresentado. Pinto (2018, p. 6) informa: "neste trabalho investiga-se a comunhão unitária, que é a titularidade comum de um patrimônio separado, na perspectiva do direito empresarial". Nesse trecho, apesar da estrutura da frase dar indícios da apresentação do objetivo geral da pesquisa, desperta-se a dúvida se não seria apenas a enunciação mais ampla do tema no qual se insere a pesquisa.

Isso se repete em outros resumos. 0 que 0 autor denomina objetivo é apresentado de maneira ampla e genérica, característica do tema, impedindo identificar o que de fato foi pesquisado e a correlação objetivo-conclusões. Esta observação pode ser exemplificada pelo trecho do resumo de Santos (2018, p. 8): "a presente pesquisa objetiva submeter o conceito de interesse público à investigação crítica 
[...]". Além disso, o resumo não apresenta as conclusões, o que impossibilita analisar se a pesquisa atingiu o objetivo proposto.

Outro dado que chama atenção é a diversidade de formas de apresentação do objetivo do trabalho. É recorrente o uso de expressões como: a "tese tem por escopo"; "a tese propõe"; a "tese tem por objeto". 0 que pode ser exemplificado por: "A presente tese tem por escopo contribuir para o fortalecimento das garantias individuais afetas ao processo de execução penal, com foco no princípio do juiz natural" (MILANEZ, 2017, p. 8). Assim como na contagem de palavras relacionadas aos itens do resumo, a presença do objetivo também foi muito recorrente a partir da observação da análise de conteúdo.

A terceira categoria analisada diz respeito ao método. 0 Gráfico 9 demonstra que palavras relacionadas ao método aparecem apenas em 13 resumos. Entretanto, o gráfico 10, que apresenta os dados da análise de conteúdo, evidencia que 9 resumos apresentam 0 método de forma explícita e 7 de forma implícita, totalizando 16. E do total de 45 resumos analisados, 29 deles não fazem menção alguma ao método utilizado na tese.

A análise dos resumos demonstrou, ainda, que quando há algum tipo de menção ao método, esta é feita de maneira parcial. Ou seja, diz respeito apenas à coleta de dados, a um capítulo do trabalho ou a alguma pesquisa pontual (jurisprudência, documentos etc.), e não ao tipo de pesquisa e ao percurso metodológico da tese como um todo. Ao descrever o método da pesquisa, espera-se que sejam indicadas: a tipologia (quanto à abordagem, aos objetivos e aos procedimentos), o campo de aplicação, o universo e amostra ou seleção (se houver), os instrumentos utilizados e a forma de organização, análise e apresentação dos dados.

Este trecho do resumo, por exemplo, faz menção a apenas uma parte da pesquisa: "a revisão bibliográfica sobre o tema é relacionada com os indicadores sociais resultantes dos relatórios que cuidam das condições de trabalho de acordo com o gênero no Brasil” (CIRINO, 2017, p. 11). Da mesma forma, o resumo da tese de Sousa (2017, p. 9) apresenta indícios de uma das partes da pesquisa, ao afirmar: "para demonstrar o pluralismo, analisar-se-á os conceitos formulados pela legislação, jurisprudência e literatura jurídica nas situações que envolvem a terminalidade da vida [...]". 0 autor indica ainda o método tipológico como forma de perscrutar novas possiblidades às situações terminais.

Alves (2019, p. 6) indica o método e parte do procedimento utilizado para pesquisa: "o método de análise foi preponderantemente dedutivo, a partir de levantamento bibliográfico jurídico e econômico". Porém, demais elementos para a descrição da trajetória metodológica do trabalho como um todo não são apresentados. 
Além disso, foram identificados métodos não convencionais de pesquisa, como "método interpretativo transversal", "método foucaultiano", "método indiciário de Carlo Ginzburg", "método genético-diacrônico" e o uso de teorias para análise de dados/achados sugerindo de forma implícita 0 uso da metateoria. Em Lobo $(2019$, p. 8) a seguinte frase aponta um desses métodos e seu uso: "aplicando-se 0 método indiciário de Carlo Ginzburg, foram analisadas as principais gazetas da imprensa política paranaense, entre 1888 e 1889". Tal informação, contudo, não apresenta o percurso metodológico da pesquisa como um todo.

Três teses apresentam a trajetória metodológica mais completa que as demais. Brighente (2019) e Wacheleski (2019) indicam o tipo de pesquisa desenvolvida e as fontes utilizadas. Brighente (2019) descreve sua pesquisa como sendo de abordagem descritiva e qualitativa com a utilização de fontes documentais como os processos criminais da segunda metade do século XIX. Wacheleski (2019, p. 9) apresenta sua pesquisa como teórica "com enfoque sobretudo nas fontes bibliográficas e documentais". Por fim, Arnt Ramos (2019) indica o método hipotético-dedutivo e o procedimento bibliográfico como descrição do método utilizado na tese.

No que se refere à presença da categoria "resultados" e "conclusões" o que se percebeu na área do Direito é praticamente a ausência de resultados. 0 gráfico 9 apresenta apenas uma ocorrência de palavra relaciona aos resultados. Dessa forma, como afirmado anteriormente e devido às características da área, a resultados/conclusões representam uma única categoria nesta pesquisa. Sob um olhar quantitativo, nove resumos contêm palavras relacionadas às conclusões (GRÁFICO 9).

A análise qualitativa revelou que os resultados/conclusões são ausentes em 14 resumos analisados nesta pesquisa. Em outros 15 resumos estes itens aparecem de forma explícita e em 16 de forma implícita (GRÁFICO 10). Observou-se que mesmo que os resultados/conclusões sejam apresentados, nem sempre é possível identificar a correlação objetivos-conclusões.

No próximo exemplo, o resumo trata sobre o tema na maior parte do texto e de modo implícito indica o que poderíamos considerar a conclusão do trabalho, em função sobretudo da sua localização na parte final do resumo:

A incorporação de ferramentas de Análise Econômica do Direito permite a identificação de elementos de crise na interpretação doutrinária e jurisprudencial do princípio da função social da empresa, assim como a proposição de diretrizes que permitam a superação do paradigma, construindo uma funcionalização que não afete a segurança jurídica e que atribua conteúdos ao princípio a partir da racionalidade econômica, mensurando externalidades e possibilitando a transição da função social para a função socioeconômica da empresa (DAL POZZO, 2017, p. 6). 
Por outro lado, no resumo da tese de Macedo (2018, p. 9) não foi possível reconhecer se as seguintes frases são o objetivo ou a conclusão da tese: "a presente tese propõe a releitura da interpretação feita pelo Supremo Tribunal Federal do regime constitucional de repartição de competências", seguida de: "a tese propõe uma compreensão dinâmica, complexa e não essencialista da federação e, consequentemente, da repartição de competências".

Por outro lado, Câmara (2017b, p. vi) apresenta o objetivo de forma explícita: "poder-se-ia indagar se o tribunal foi controlado pelo Executivo federal, de maneira a corroborar suas decisões”. Da mesma forma, os resultados/conclusões também puderam ser identificados de forma explícita e em correlação ao objetivo geral proposto: "na análise das 65 representações julgadas, entre 1965 e 1968, o tribunal se mostrou comprometido com a função de decidir sobre a Constituição, ao mesmo tempo em que tentou se resguardar contra as alterações que diminuíssem sua autonomia".

Há ainda um resumos que apresentam os resultados/conclusões como proposta ou proposições, como no seguinte exemplo: "Proponho aqui uma confissão de fé no Direito e na potencialidade que guarda de mudança, buscando alcançar a ideia de que as relações provenientes dos amores e dos afetos são aquilo que traz o indivíduo à vida, aquilo que traz significado ao corpo (FERREIRA, 2019, p. 11).

Em uma análise geral, observamos que o diagnóstico de Nobre (2004) sobre o "modelo de parecer" ainda é uma racionalidade presente na produção de teses no Direito. Isso ficou explicitado pelo uso de expressões como "defende-se", "argumenta-se", "propõe-se" as quais parecem traduzir mais a defesa de um posicionamento e menos a resposta a um problema ou pergunta de pesquisa (GRÁFICO 11). Nesse sentido, aliás, apenas um resumo faz menção explicita ao problema de pesquisa (VENTURI, 2019).

Gráfico 11: Teses que contém palavras que demonstram características do modelo de parecer.

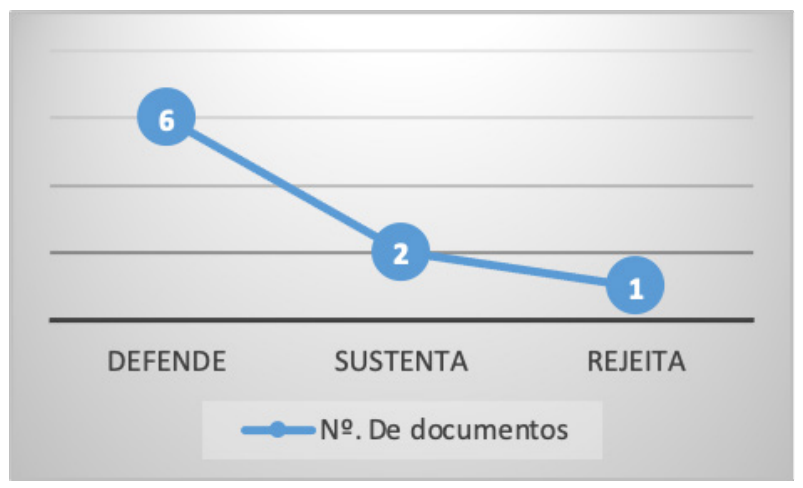

FONTE: As autoras (2020) 
De acordo com o Gráfico 11, a palavra defende é utilizada em seis resumos. No trecho a seguir, 0 autor apresenta os resultados resultados/conclusões da seguinte forma:

[...] assim, defende-se que o pacto antenupcial pode promover e instrumentalizar a autonomia sucessória dos cônjuges, que, em exercício pleno de liberdade positiva a respeito de sua esfera patrimonial, podem dispor a respeito de sua mútua exclusão da concorrência sucessória (FRANK, 2017, p. 9, grifo nosso).

É possível também citar outros dois exemplo do uso da mesma forma de argumento para as considerações finais:

Defende-se uma democracia crítico-descolonial para além da representação, nas dimensões normativas da participação, deliberação e radicalidade, como decisivo critério para a redução de injustiça e fonte de inspiração para busca de alternativas no contexto latino-americano [...] (BERCLAZ, 2017, p.14, grifo nosso).

0 resumo de Valle (2017, p. X, grifo nosso) apresenta duas palavras que evidenciam o seu uso na linha do que Nobre (2004) chama de modelo de parecer. A primeira na frase: "e também se sustenta a extinção do regime geral de prerrogativas estabelecido na Lei n. 8666/93. E a segunda: "e sustentase 0 contrato administrativo de longa duração como instrumento de governo estabilizador de políticas públicas e promotor de desenvolvimento".

Dos 45 resumos analisado, apenas 10 resumos apresentam todos os itens obrigatórios do resumo ainda que de forma implícita (tema, objetivos, método, resultados/conclusões). Desses, apenas quatro estão estruturados conforme a NBR 6028/2003 e contém todos os elementos descritos de forma explícita, permitindo o reconhecimento inicial completo da pesquisa a partir do resumo. São eles: Cirino (2017), Ferrazzo (2019), Brighente (2019), Wacheleski (2019). Destaque-se que apesar do método ter sido indicado explicitamente nos resumos dessas teses, eles apresentam dados parciais ou de uma específica da pesquisa.

\section{CONSIDERAÇÕES FINAIS}

Nesta pesquisa foram discutidos aspectos epistemológicos caracterizadores da pesquisa em direito no Brasil, com foco nos programas de pós-graduação, em que o PPGD/UFPR foi descrito. 0 resumo foi apresentado como elemento fundamental para a representação do conteúdo e dos recursos metodológicos das teses. 0 corpus da pesquisa foi formado por 45 resumos de teses defendidas entre 2017 e 2019 no PPGD/UFPR. Esses resumos foram identificados, analisados e categorizados por meio de duplo recurso metodológico de análise de conteúdo (via software e manualmente), conforme a existência ou ausência dos recursos metodológicos apresentados nos resumos. 
Contatou-se fragilidade metodológica e, portanto, científica na escrita dos resumos, uma vez que apenas 10 teses continham a representação de todos os recursos metodológicos (tema, objetivos, método, resultados/conclusões. Os outros resumos não cumprem plenamente o papel de representar, de forma condensada, e informar o leitor sobre os propósitos da pesquisa, como ela foi feita e a que conclusões o autor chegou ao final do estudo.

Essa constatação demonstra indícios de ausência de elementos metodológicos fundamentais em pesquisas do Direito. Do total de resumos analisados, 29 deles não fizeram indicação alguma da trajetória metodológica percorrida para a construção da tese. Porém, é preciso reconhecer que a análise apenas dos resumos pode limitar o espectro de análise. A afirmação categórica dessa constatação demandaria uma pesquisa mais ampla com a análise dos capítulos de introdução, métodos e conclusões da tese. 0 que se viu, nos sumários das teses selecionadas, é que, em sua maioria, não dispõem de um capítulo ou item exclusivo dedicado ao desenho metodológico da pesquisa, fato que diz muito sobre essa aparente marginalidade da metodologia no campo da produção científica do Direito, ainda que se possa discutir especificidades metodológicas da área.

Pode-se ainda reafirmar o que Nobre (2004) constatou com suas pesquisas, há uma indistinção entre a escrita da prática profissional e a teoria/pesquisa acadêmica. Nesse contexto, observou-se que a escrita seguindo o "modelo de parecer" está presente nas teses analisadas nesta pesquisa. Acreditase ainda que a pequena carga horária da disciplina de metodologia da pesquisa do Programa de Pósgraduação em Direito pode impactar a qualidade metodológica dos trabalhos. Dessa forma, sugere-se 0 aumento dessa carga horária.

Sugere-se também como pesquisa futura a análise dos resumos das teses que forem defendidas no PPGD/UFPR em 2020, bem com o estudo dos resumos das teses de outros programas para fins de análise das mesmas variáveis e até mesmo comparação entre as diferentes realidades. A análise do conteúdo das teses como um todo também possibilitará a descoberta de outros elementos que não foram identificados nesta pesquisa.

\section{REFERÊNCIAS}

ALVES, Giovani Ribeiro Rodrigues. Operações de compra e venda de empresas sob a perspectiva da economia comportamental: previsibilidade do erro e intervenção. 2019. 215 f. Tese (Doutorado em Direito) - Setor de Ciências Jurídicas, Universidade Federal do Paraná, Curitiba, 2019. 
ARNT RAMOS, André Luiz. Segurança jurídica e enunciados normativos deliberadamente indeterminados: 0 caso da função social do contrato. 2019. 224 f. Tese (Doutorado em Direito) Setor de Ciências Jurídicas, Universidade Federal do Paraná, Curitiba, 2019. Disponível em: http://hdl. handle.net/1884/65931. Acesso em: 4 mar. 2021.

ASSOCIAÇÃO BRASILEIRA DE NORMAS TÉCNICAS. NBR 6028: informação e documentação: resumos: apresentação. Rio de Janeiro: ABNT, nov. 2003.

BARDIN, Laurence. Análise de conteúdo. São Paulo, SP: Edições 70, 2011.

BERCLAZ, Márcio Soares. Da injustiça à democracia: ensaio para uma justiça de libertação a partir da experiência zapatista. 2017. 729 f. Tese (Doutorado em Direito) - Setor de Ciências Jurídicas, Universidade Federal do Paraná, Curitiba, 2017. Disponível em: http://hdl.handle.net/1884/52850. Acesso em: 4 mar. 2021.

BRIGHENTE, Liliam Ferraresi. A condição jurídica criminal do escravo no Império do Brasil: um estudo a partir de Castro, província do Paraná (1850-1888). 2019. 520 f. Tese (Doutorado em Direito) Universidade Federal do Paraná, Setor de Ciências Jurídicas, Programa de Pós-Graduação em Direito.

CÂMARA, Edna Torres Felicio. Os dilemas do estado em rede na era da informação: articulações entre 0 direito ao desenvolvimento e a liberdade informática. 2017. 280 f. Tese (Doutorado em Direito) - Setor de Ciências Jurídicas, Universidade Federal do Paraná, Curitiba, 2017a. Disponível em: http://hdl.handle.net/1884/55082. Acesso em: 4 mar. 2021.

CÂMARA, Heloísa Fernandes. STF na ditadura militar brasileira: um tribunal adaptável?. 2017. 273 f . Tese (Doutorado em Direito) - Setor de Ciências Jurídicas, Universidade Federal do Paraná, Curitiba, 2017b. Disponível em: http://hdl.handle.net/1884/48195. Acesso em: 4 mar. 2021.

CIRINO, Samia Moda. (Des)construção da identidade de gênero: inserção crítica ao sujeito do feminismo e o reconhecimento do trabalho da mulher. 2017. $221 \mathrm{f}$. Tese (Doutorado em Direito) Setor de Ciências Jurídicas, Universidade Federal do Paraná, Curitiba, 2017. Disponível em: http://hdl. handle.net/1884/49416. Acesso em: 4 mar. 2021.

COORDENADAÇÃO DE APERFEIÇOAMENTO DE PESSOAL DE NÍVEL SUPERIOR (CAPES). Sobre a avaliação. Brasília, DF: CAPES, 1 abr. 2014. Disponível em: https://www.capes.gov.br/avaliacao/ sobre-a-avaliacao. Acesso em: 1 ago. 2020.

COORDENADAÇÃO DE APERFEIÇOAMENTO DE PESSOAL DE NÍVEL SUPERIOR (CAPES). GeoCAPES: sistema de informações georreferenciadas. Brasília: CAPES, 2020. Disponível em: https://geocapes. capes.gov.br/geocapes/ Acesso em: 26 maio 2020.

COORDENADAÇÃO DE APERFEIÇOAMENTO DE PESSOAL DE NÍVEL SUPERIOR (CAPES). Documento de área: área 26 Direito. Brasília, DF: CAPES, 2019. Disponível em: http://capes.gov.br/images/ Documento_de_área_2019/Direito.pdf Acesso em 26 maio 2020.

DADOS básicos do programa. COORDENADAÇÃO DE APERFEIÇOAMENTO DE PESSOAL DE NÍVEL SUPERIOR (CAPES). Plataforma Sucupira: coleta CAPES. Brasília, DF: CAPES, 2020. Disponível em: https://sucupira.capes.gov.br/. Acesso em: 10 maio 2020. 
FERRAZZO, Débora. Democracia comunitária e pluralismo jurídico: desafios à factibilidade da descolonização constitucional na Bolívia. 2019. 402 f. Tese (Doutorado em Direito) - Setor de Ciências Jurídicas, Universidade Federal do Paraná, Curitiba, 2019.

FERREIRA, Gustavo Bussmann. Identidades out of joint: 0 direito como potência. 2019. 319 f. Tese (Doutorado em Direito) - Setor de Ciências Jurídicas, Universidade Federal do Paraná, Curitiba, 2019.

FRAGALE FILHO, Roberto; VERONESE, Alexandre. A pesquisa em Direito: diagnóstico e perspectivas. Revista Brasileira de Pós-Graduação, v. 1, n. 2, 11. Disponível em: http://ojs.rbpg. capes.gov.br/index.php/rbpg/article/view/40/37. Acesso em: 20 maio 2020.

FRANK, Felipe. Autonomia sucessória e pacto antenupcial: problematizações sobre o conceito de sucessão legítima e sobre o conteúdo e os efeitos sucessórios das disposições pré-nupciais. 2017. 208 f. Tese (Doutorado em Direito) - Setor de Ciências Jurídicas, Universidade Federal do Paraná, Curitiba, 2017. Disponível em: http://hdl.handle.net/1884/52021. Acesso em: 4 mar. 2021.

GUIMARÃES, José Augusto Chaves. 0 resumo como instrumento para a divulgação e a pesquisa científica. Revista Brasileira de Educação Especial, v. 11, n. 1, p. 3-16, abr. 2005. Disponível em: https://www.abpee.net/homepageabpee04_06/artigos_em_pdf/revista11numero1pdf/1joseaugusto. pdf. Acesso em: 14 jun. 2020.

HANSEN, Thiago Freitas. Codificar e conservar: ciência e pensamento jurídico na formação do Código Florestal Brasileiro de 1934. 2018. 227 p. Tese (Doutorado em Direito) - Setor de Ciências Jurídicas, Universidade Federal do Paraná, Curitiba, 2018. Disponível em: http://hdl.handle. net/1884/58064. Acesso em: 4 mar. 2021.

HASSON, Felipe. Direito internacional privado e liberdades: a dimensão funcional voltada ao desenvolvimento humano. 2018. 235 p. Tese (Doutorado em Direito) - Setor de Ciências Jurídicas, Universidade Federal do Paraná, Curitiba, 2018. Disponível em: http://hdl.handle.net/1884/58100. Acesso em: 4 mar. 2021.

INTERNATIONAL STANDARD ORGANIZATION. ISO 214:1976: documentation -abstracts for publications and documentation. Vernier, Geneva

Switzerland: ISO, 1976. Disponível em: http://www.iso.org/iso/catalogue_detail.htm?csnumber=4084. Acesso em: 4 mar. 2021.

LINHAS de pesquisa. COORDENADAÇÃO DE APERFEIÇOAMENTO DE PESSOAL DE NÍVEL SUPERIOR (CAPES). Plataforma Sucupira: coleta CAPES Brasília, DF: CAPES, 2016. Disponível em: https:// sucupira.capes.gov.br/. Acesso em: 10 maio 2020.

LOBO, Judá Leão. Os artigos anônimos de João Gomes: um episódio da disputa pelo sentido do ato adicional no Brasil Império. 2019. 220 f. Tese (Doutorado em Direito) - Setor de Ciências Jurídicas, Universidade Federal do Paraná, Curitiba, 2019.

MACEDO, José Arthur Castillo de. Encruzilhadas do federalismo: transfederalismo, cooperação, constitucionalismo e democracia. 2018. 223 f. Tese (Doutorado em Direito) - Setor de Ciências Jurídicas, Universidade Federal do Paraná, Curitiba, 2019. 
MILANEZ, Bruno Augusto Vigo. 0 princípio do juíz natural no processo de execução penal. 2017. 280 p. Tese (Doutorado em Direito) - Setor de Ciências Jurídicas, Universidade Federal do Paraná, Curitiba, 2017. Disponível em: http://hdl.handle.net/1884/53677. Acesso em: 4 mar. 2021.

NOBRE, Marcos. Apontamentos sobre a pesquisa em Direito no Brasil. Novos Estudos Cebrap. São Paulo. jul. 2004. p. 03-19. Disponível em: https://bibliotecadigital.fgv.br/dspace/bitstream/ handle/10438/2779/Pesquisa_Direito_Cadernos_Direito_GV.pdf?sequence=1\&isAllowed=y. Acesso em: 20 maio 2020.

\section{OBJETIVOS. UNIVERSIDADE FEDERAL DO PARANÁ (UFPR). Programa de Pós-graduação em} Direito. 2020. Disponível em: http://www.ppgd.ufpr.br/?page id=4213 .Acesso em: 22 jun. 2020.

PINTO, Rafael dos Santos. A dogmática da comunhão unitária no direito empresarial: um estudo sobre a insuficiência dos tipos legais que disciplinam a pluralidade subjetiva patrimonial em operações econômicas. 2018. 177 p. Tese (Doutorado em Direito) - Setor de Ciências Jurídicas, Universidade Federal do Paraná, Curitiba, 2018. Disponível em: http://hdl.handle.net/1884/58656. Acesso em: 4 mar. 2021.

POZZO, Emerson Luís Dal. Paradigmas da função social da empresa em crise. 2017. 299 f . Tese (Doutorado em Direito) - Setor de Ciências Jurídicas, Universidade Federal do Paraná, Curitiba, 2017. Disponível em: http://hdl.handle.net/1884/52993. Acesso em: 4 mar. 2021.

SANTOS, Luasses Gonçalves dos. 0 direito administrativo em desencanto: 0 interesse público sob a crítica da teoria crítica. 2018. 299 p. Tese (Doutorado em Direito) - Setor de Ciências Jurídicas, Universidade Federal do Paraná, Curitiba, 2018. Disponível em: http://hdl.handle.net/1884/58123. Acesso em: 4 mar. 2021.

SIMÕES, Maria da Graça Melo. Resumo documental e literatura científica: origem, desenvolvimento e consolidação. Páginas A\&B: arquivos e bibliotecas, v. 0, n. 0, p. 15-36, 20 jul. 2015. Disponível em: http://ojs.letras.up.pt/index.php/paginasaeb/article/view/663. Acesso em: 4 jul. 2020.

SOUSA, Paulo Henrique Martins de. A insuficiência do pluralismo conceitual nas decisões de fim de vida. 2017. 277 f. Tese (Doutorado em Direito) - Setor de Ciências Jurídicas, Universidade Federal do Paraná, Curitiba, 2017. Disponível em: http://hdl.handle.net/1884/55311. Acesso em: 4 mar. 2021.

SPERA, Henrique Baraldi; MUGNAINI, Rogério. Características da produção científica em direito: desafios para a avaliação. In: ENCONTRO NACIONAL DE PESQUISA EM CIÊNCIA DA INFORMAÇÃO, 20., 2019. Anais eletrônicos [...]. Florianópolis, SC: UFSC, 2019. Disponível em: https:// conferencias.ufsc.br/index.php/enancib/2019/paper/view/1276. Acesso em: 20 maio 2020.

UNIVERSIDADE FEDERAL DO PARANÁ (UFPR). Conselho de Ensino, Pesquisa e Extensão. Resolução n. 69/2005-CEPE. Fixa o currículo do Programa de Pós-graduação em Direito - Mestrado e Doutorado do Setor de Ciências Jurídicas da Universidade Federal do Paraná. Programa de Pósgraduação em Direito, Curitiba, PR, 8 dez. 2005.

VALLE, Vivian Cristina Lima López. Contratos administrativos e um novo regime jurídico de prerrogativas contratuais na administração pública contemporânea: da unilateralidade ao consenso e do consenso à unilateralidade na relação contratual administrativa. 2017. 264 f. Tese (Doutorado em 
Direito) - Setor de Ciências Jurídicas, Universidade Federal do Paraná, Curitiba, 2017. Disponível em: http://hdl.handle.net/1884/53990. Acesso em: 4 mar. 2021.

VENTURI, Eliseu Raphael. 0 pós-humanismo crítico como problema de biopolítica afirmativa em filosofia contemporânea do direito. 2019. 234 f. Tese (Doutorado em Direito) - Setor de Ciências Jurídicas, Universidade Federal do Paraná, Curitiba, 2019.

WACHELESKI, Marcelo Paulo. Cidadania e reconhecimento da pessoa com deficiência a partir dos direitos humanos. 2019. 300 f. Tese (Doutorado em Direito) - Setor de Ciências Jurídicas, Universidade Federal do Paraná, Curitiba, 2019.

WEINERT, Clarann. Are all abstracts created equal? Applied Nursing Research, v. 23, n. 2, p. 106109, 1 maio 2010. DOI 10.1016/j.apnr.2008.06.003.

\section{AGRADECIMENTO}

Agradecemos a cuidadosa leitura e as valiosas sugestões feitas pela Prof. Dr. ${ }^{a}$ Leilah Santiago Bufrem, pelo Prof. Dr. Egon Bockmann Moreira e pela doutoranda Suellyn Mattos Aragão. 